\title{
ONUPHIDAE (ANNELIDA, POLYCHAETA) DA REGIÃO DE UBATUBA, LITORAL NORTE DO ESTADO DE SÃO PAULO, BRASIL
}

\author{
Eloisa H. Morgado ${ }^{1}$ \\ A. Cecília Z. Amaral ${ }^{1}$
}

\begin{abstract}
OnUphidae (ANNElida, Polychaeta) From Ubatuba, NoRTH COAST OF THE São Paulo State, BRAZIL. Ten species of onuphid polychaetes were identified from the sublitoral of Ubatuba, on the coast of the state of São Paulo, Brazil: Diopatra cuprea (Bosc, 1802); Diopatra tridentata Hartman, 1944; Kinbergonuphis difficilis (Fauchald, 1982); Kinbergonuphis fauchaldi Lana, 1991; Kinbergonuphis orensanzi (Fauchald, 1982); Kinbergonuphis tenuis (Hansen, 1882); Mooreonuphis nebulosa (Moore, 1911); Mooreonuphis pallidula (Hartman, 1965); Mooreonuphis intermedia (Kinberg, 1865); Onuphis dibranchiata Willey, 1905. A discussion on the characteristics of the species found and related species is also provided.

KEY WORDS. Onuphidae, Polychaeta, sublitoral, Ubatuba
\end{abstract}

Criada por KINBERG (1865), a família conta com 22 gêneros e cerca de 220 espécies (PAXTON 1986). Entre as principais revisões taxonômicas estão incluídas as efetuadas por FAUCHALD (1982b), com o intuito de esclarecer dúvidas que envolvem o complexo Onuphis -Nothria-Paradiopatra; por PAXTON (1986), que enfatiza as relações filogenéticas entre os gêneros da família, e por ORENSANZ (1990), que aborda a sistemática e a filogenia das famílias pertencentes a Ordem Eunicemorpha de mares antárticos e subantárticos.

Os onufideos caracterizam-se por apresentar um prostômio com cinco antenas (um par lateral anterior, um lateral posterior e uma única antena mediana), com ceratóforos distintos, dois palpos frontais e dois ventrais; olhos, quando presentes, situados entre as bases das antenas laterais. Segmento peristomial ápodo pode conter um par de cirros tentaculares (cirros occipitais). Convém mencionar que diagnoses mais antigas porém de consulta habitual (FAUVEL 1923; DAY 1967 entre outros), referem-se à presença de sete antenas, duas das quais atualmente caracterizadas como palpos frontais.

Parapódios sub-birremes, devido ao reduzido notopódio, representado pelo cirro dorsal. Parapódios anteriores (1-8) estruturalmente diferentes quanto à orientação, comprimento, desenvolvimento do lobo parapodial e tipo de cerdas. Cirros dorsais subulados, normalmente presentes em todos os setígeros, ventrais subulados ou digitiformes nos parapódios anteriores e em forma de "almofadas" ventrais glandulares, nos demais. Brânquias presentes na maioria das espécies, podendo ser simples, ramificadas, pectinadas ou espiraladas; dois ou quatro cirros anais.

1) Departamento de Zoologia, Instituto de Biologia, Universidade Estadual de Campinas. Caixa Postal 6109, 13083-970 Campinas, São Paulo, Brasil. 
Como resultado da redução dos notopódios, as notocerdas, quando presentes, são reduzidas e internas ao cirro dorsal. Parapódios modificados (1-8) com ganchos simples a pseudocompostos, cerdas pectinadas e/ou limbadas. Os demais parapódios possuem cerdas pectinadas, limbadas simples e compostas espinígeras, raramente falcígeras e ganchos subaciculares encapuzados.

Probóscide eversível equipada com um par de mandíbulas ventrais, e quatro a cinco pares de maxilas dorsais. Preferencialmente tubícolas.

Como importantes caracteres genéricos para a família podem ser considerados: presença de cirros tentaculares, tipo de brânquias, comprimento das antenas e dos ceratóforos, número e modificações dos parapódios anteriores, cerdas pectinadas, ganchos pseudocompostos, presença de grandes ganchos medianos e de cerdas compostas espinígeras.

Caracteres específicos incluem número de anéis dos ceratóforos, origem das brânquias e dos ganchos subaciculares, número e forma dos dentes dos ganchos pseudocompostos e número de setígeros com cirros ventrais digitiformes.

A família Onuphidae, assinalada para costa brasileira desde 1865 quando Kinberg descreveu Diopatra brasiliensis e Onuphis intermedia, é ainda insuficientemente conhecida. Somente a partir da década de 70 foi melhor estudada, conforme enfatizado por LANA (1991), contando atualmente com 28 espécies.

Este trabalho descreve as espécies de Onuphidae coletadas na região de Ubatuba, litoral Norte do Estado de São Paulo, compreendida entre as illhas Anchieta

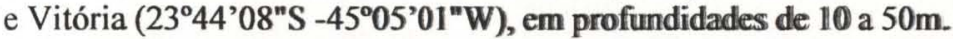

Para as descrições e definições genéricas adotou-se a terminologia proposta por PAXTON (1986).

A coleção examinada encontra-se depositada no Departamento de Zoologia, Instituto de Biologia, Universidade Estadual de Campinas.

\section{Onuphidae Kinberg, 1865 \\ Onuphinae, 1865}

\section{Diopatra Audovin \& Mine Edwards, 1833}

\section{Diopatra cuprea (Bosc, 1802)}

Nereis cuprea Bosc, 1802: 142.

Diopatra cuprea; Hartman, 1944: 54-55, est. 1, figs 9-14. - Pettibone, 1963: 250-253, fig 66 - Gathof, 1984: 39-9-10.

Diopatra cf. cuprea; Nonato \& Luna, 1970: 73-74.

Material examinado. Dois exemplares: um completo com 100 setígeros, medindo cerca de $46 \mathrm{~mm}$ de comprimento e um exemplar incompleto, com a região anterior em regeneração. Em fundos de areia grossa, a 10 e $45 \mathrm{~m}$ de profundidade.

Descrição. Corpo cilíndrico na região anterior e dorso ventralmente achatado, na posterior. Ceratóforos das antenas dorsais com 10-14 anelaçōes. Brânquias a partir do quinto setígero, espiraladas aproximadamente até o $50^{\circ}$ e simples na região posterior. Cirros dorsais longos e digitiformes alcançando a extremidade do 
lóbulo parapodial. Cirros ventrais curtos e subulados até o quarto setígero, cônico no quinto e em forma de almofada nos seguintes. Ganchos pseudocompostos bidentados encapuzados ventrais até o quarto setígero, acompanhados de delgadas cerdas limbadas dorsais. A partir do quinto setígero, cerdas limbadas robustas e cerdas pectinadas com ramos de comprimento desigual. Ganchos sub-aciculares bidentados encapuzados presentes a partir do $12^{\circ}$ setígero. Parapódios posteriores com 5-6 acículos afilados.

Distribuição. Costa leste norte-americana (Massachusets e Flórida); Golfo do México; Antilhas; Panamá; costa oeste-africana; Pacífico tropical. Brasil: costa nordeste, Alagoas e Sergipe; sudeste, São Paulo (Ubatuba).

Discussão. Os exemplares examinados correspondem em grande parte, às descrições de PETTIBONE (1963) e NONATO \& LUNA (1970), exceto com relação ao número de anéis nos ceratóforos e de setígeros providos de brânquias. Segundo HARTMAN (1944), Diopatra cuprea assemelha-se a D. ornata Moore (1911) em muitos aspectos, mas desta se distingue pela forma e disposição das papilas dos ceratóstilos, em fileiras longitudinais alternadas, de diminutas a grandes papilas arredondadas, e pela forma dos ganchos bidentados dos primeiros setígeros, com dente apical fortemente oblíquo e dente acessório aproximadamente paralelo ao principal.

\section{Diopatra tridentata Hartman, 1944}

? Diopatra brasiliensis; Kinberg, 1865: 559.

Diopatra tridentata Hartman, 1944: 61-63, est. 2, figs 37-43 e est. 17, figs 335-336. - Nonato \& Luna, 1970: 75-76. - Gardiner, 1975: 185, fig. 23j-n. - Temperini, 1981: 30. - Lana, 1984: 144-146, figs 141-142. - Gathof, 1984: 39-41, figs 39-7, 8a-i.

Material examinado. Nove exemplares dos quais dois completos; o maior com cerca de 65 setígeros, medindo $18 \mathrm{~mm}$ de comprimento. Em fundos de areia fina e silte, entre 10 e $50 \mathrm{~m}$ de produndidade.

Descrição. Prostômio com um par de pequenos pontos ocelares entre as bases das antenas laterais. Antenas dorsais longas com 7-10 anelações nos ceratóforos, sendo o anel distal mais longo que os demais. Brânquias espiraladas presentes do $4-5^{\circ}$ ao $30^{\circ}$ setígero. Parapódios dos primeiros quatro setígeros bem desenvolvidos, providos de cirros dorsais, ventrais e lobos pós-setais longos: ganchos encapuzados pseudocompostos tridentados, capilares limbadas e acículos com extremidades afiladas. A partir do quinto setígero os ganchos pseudocompostos são substituídos por cerdas limbadas. Ganchos sub-aciculares bidentados presentes a partir do nono setígero. Parapódios medianos e posteriores com cerdas pectinadas, bilimbadas e acículos geniculados.

Distribuição. Costa pacífica americana, da Califórnia ao Equador; costa atlântica americana, da Carolina do Norte ao sul-sudeste do Brasil: Espírito Santo, Rio de Janeiro, São Paulo, Paraná e Santa Catarina.

Discussão. Os exemplares analisados apresentam características coincidentes com as referidas por HARTMAN (1944), não concordando apenas quanto ao número de brânquias. Diopatra tridentata diferencia-se das demais espécies do 
gênero pela presença de ganchos encapuzados tridentados e de lobos prolongados nos parapódios anteriores, bem como pela estrutura anelada do tubo, conforme descrita em NoNATO \& LUNA (1970). Diopatra brasiliensis, descrita para a costa brasileira (Rio de Janeiro) por KINBERG (1865), seria, segundo HARTMAN (1944), a única outra espécie do gênero com ganchos tridentados. No entanto, a descrição de Kinberg, insuficiente para permitir uma comparação detalhada das duas espécies, fez com que Hartman as considerasse distintas. Conforme procedimento já adotado por NONATO \& LUNA (1970) e LANA (1984), a espécie foi considerada como tridentada e brasiliensis como sinonimia, com as mesmas reservas mencionadas por Lana.

Kinbergonuphis Fauchald, 1982

\section{Kinbergonuphis difficilis (Fauchald, 1982) \\ Tab. I}

Onuphis (Onuphis) difficilis Fauchald, 1982a: 203-205, fig. 1.

Kinbergonuphis difficilis; Fauchald, 1982b: 18, fig. 8a. - Lana, 1984: 165-167, fig. 184.

Material examinado. Quatro exemplares incompletos; o maior com 84 setígeros, medindo $31 \mathrm{~mm}$ de comprimento. Em fundos de areia muito fina e silte médio, entre 25 e $50 \mathrm{~m}$ de profundidade.

Descrição. Corpo relativamente robusto. Ceratóforos das antenas dorsais com até seis anelações. Antenas laterais posteriores com ceratóstilos mais longos atingindo o $4-6^{\circ}$ setígero. Brânquias ramificadas, com dois filamentos a partir do sexto setígero e 4-5 filamentos em parapódios medianos. Cirros dorsais longos, subulados. Cirros ventrais cirriformes nos 6-7 primeiros setígeros e lobos pós-setais digitiformes até o $14-16^{\circ}$. Ganchos pseudocompostos tridentados, com dente distal longo e afilado, excedendo o bordo das valvas hialinas, nos cinco setígeros anteriores. Grandes ganchos tridentados simples, com dente mediano robusto, bem desenvolvido, presentes do terceiro ao oitavo setígero. Ganchos sub-aciculares bidentados a partir do $14-16^{\circ}$ setígero.

Distribuição. Atlântico Sul - Uruguai e Brasil: costa sudeste, São Paulo e Paraná.

Discussão. FAUCHALD (1982a) com base em material da costa uruguaia, referido por ORENSANZ (1974) como Onuphis setosa Kinberg (1865), descreveu duas novas espécies, Onuphis (Onuphis) difficilis e Onuphis (Onuphis) orensanzi, que após revisão do próprio FAUCHALD (1982b) foram incluídas no gênero Kinbergonuphis. Kinbergonuphis orensanzi (Fauchald, 1982), espécie também registrada na área considerada, diferencia-se de $K$. difficilis por apresentar brânquias com no máximo três filamentos em parapódios medianos, menor número de setígeros anteriores com lobos pós-setais digitiformes e pela presença de ganchos sub-aciculares mais anteriores (Tab. I). Kinbergonuphis tenuis (Hansen, 1882), registrada para o Rio de Janeiro, assemelha-se a $K$. difficilis quanto a vários caracteres, mas diferencia-se pelo menor número de filamentos branquiais e de setígeros com lobos pós-setais digitiformes. 
Tabela I. Principais características de espécies de Kinbergonuphis registradas para o Litoral Norte de São Paulo.

\begin{tabular}{|c|c|c|c|c|c|}
\hline & K. difficilis & K. fauchaldi & K. orensanzi & K. tenuis & K. nonatoi \\
\hline Ceratóforo, número máximo de anéis & cerca de 6 & cerca de 4 & $\begin{array}{l}\text { cerca de } 4 \\
\text { (indistintos) }\end{array}$ & $4-5$ & 5 \\
\hline $\begin{array}{l}\text { Ceratóstilo mais longo alcançando } \\
\text { os setigeros }\end{array}$ & $\begin{array}{c}4-6 \\
\text { (látero posterior) }\end{array}$ & 3 & 5 & $4-7$ & $\begin{array}{c}11 \\
\text { (látero posterior) }\end{array}$ \\
\hline $\begin{array}{l}\text { Bránquias, primeiro par no setigero / } \\
\text { número máximo de filamentos }\end{array}$ & $\begin{array}{c}6 / 2,4-5 \\
\text { (ramificadas) }\end{array}$ & $\begin{array}{l}7-8 / 3 \\
\text { (simples e } \\
\text { ramificadas) }\end{array}$ & $\begin{array}{c}6 / 3 \\
\text { (simples) }\end{array}$ & $\begin{array}{c}6 / 2-3 \\
\text { (ramificadas) }\end{array}$ & $\begin{array}{c}7-8 / \text { até } 6 \\
\text { (simples, } \\
\text { pectinadas) }\end{array}$ \\
\hline $\begin{array}{l}\text { Cirro ventral cirriforme presente nos } \\
\text { setígeros }\end{array}$ & $1-6 / 7$ & $1-5 / 6$ & $\begin{array}{c}1-5 / 6 \\
\text { (transicional) }\end{array}$ & $1-6$ & $1-6 / 8$ \\
\hline $\begin{array}{l}\text { Lobo pós-setal digitiforme presente } \\
\text { nos setigeros }\end{array}$ & $1-14 / 16$ & $1-12$ & $1-10$ & $1-10 / 12$ & $1-15$ \\
\hline $\begin{array}{l}\text { Ganchos pseudo compostos triden- } \\
\text { tados presentes nos setigeros }\end{array}$ & $1-5$ & $1-4$ & $1-4$ & $1-5$ & $1-5$ \\
\hline $\begin{array}{l}\text { Grandes ganchos medianos tridenta- } \\
\text { dos presentes nos setigeros }\end{array}$ & $\begin{array}{c}3-8 \\
\text { (simples) }\end{array}$ & $\begin{array}{c}4-7 \\
\text { (simples) }\end{array}$ & $\begin{array}{c}3-6 \\
\text { (simples) }\end{array}$ & $\begin{array}{c}6 \\
\text { (pseudocomposto) }\end{array}$ & $\begin{array}{l}6-21 / 22 \\
\text { (simples) }\end{array}$ \\
\hline $\begin{array}{l}\text { Ganchos subaciculares bidentados } \\
\text { a partir dos setigeros }\end{array}$ & $14-16$ & 13 & 13 & $14-15$ & $22-23$ \\
\hline
\end{tabular}

\section{Kinbergonuphis fauchaldi Lana, 1991}

Tab. I

Kinbergonuphis fauchaldi Lana, 1991: 286-288, fig. 3.

Material examinado. Cinco exemplares incompletos: o maior com 100 setígeros, medindo $20 \mathrm{~mm}$ de comprimento. Em fundos de areia média, areia fina e silte médio, entre 35 e $45 \mathrm{~m}$ de profundidade.

Descrição. Região anterior com pigmentação escura em bandas transversais dorsais e ventrais. Ceratóforos das antenas dorsais com cerca de quatro anelações basais e anel distal longo; ceratóstilo mais longo atingindo o terceiro setígero. Brânquias a partir do oitavo setígero, simples a princípio, com até três filamentos nos parapódios medianos e novamente simples na região posterior. Cirros ventrais cirriformes nos 5-6 primeiros setígeros e lobos pós-setais digitiformes até o $12^{\circ}$. Ganchos pseudocompostos nitidamente tridentados nos quatro setígeros anteriores, substituídos por cerdas limbadas curtas a partir do quinto setígero. Grandes ganchos medianos tridentados simples, com dente apical pouco desenvolvido do quarto ao sétimo setígeros. Ganchos sub-aciculares bidentados presentes a partir do $13^{\circ}$ setígero.

Distribuição. Brasil: costa sudeste (Paraná e São Paulo).

Discussão. Os exemplares examinados correspondem perfeitamente à descrição de LANA (1991). Kinbergonuphis orensanzi (Fauchald, 1982) da costa uruguaia e $K$. nonatoi, também descrita por LANA (1991) para a costa sudeste do Brasil, são espécies próximas (Tab. I). Kinbergonuphis orensanzi assemelha-se a $K$. fauchaldi por possuir ganchos pseudocompostos tridentados apenas nos quatro primeiros setígeros e ganchos sub-aciculares a partir do $13^{\circ}$; diferencia-se, no entanto, principalmente pela presença de brânquias simples sempre a partir do sexto setígero. Kinbergonuphis nonatoi aproxima-se de $K$. fauchaldi quanto ao aparecimento das primeiras brânquias, $7-8^{\circ}$ setígero, mas distingue-se por apresentar 
brânquias pectinadas com até seis filamentos em parapódios medianos e posteriores, maior número de setígeros anteriores com grandes ganchos medianos simples tridentados (sexto ao $21-22^{\circ}$ setígero) e pela presença de ganchos subaciculares tridentados a partir de setígeros mais posteriores $\left(22-23^{\circ}\right)$.

\section{Kinbergonuphis orensanzi (Fauchald, 1982)}

Tab. 1

Omuphis (Onuphis) orensanzi Fauchald, 1982a: 205, fig. 2.

Kinbergonuphis orensanzi; Fauchald, 1982b: 27-28, fig. 8b. - Lana, 1984: 163-164, fig. 183.

Material Examinado. Um exemplar incompleto, com 54 setígeros e $10 \mathrm{~mm}$ de comprimento. Em fundo de areia fina, a $25 \mathrm{~m}$ de profundidade.

Descrição. Prostômio com dois pares de ocelos (punctiformes): um par na base das antenas frontais e outro na base das antenas laterais anteriores. Ceratóforos com cerca de quatro anelações indistintas. Ceratóstilos das antenas laterais posteriores atingindo o quinto setígero. Brânquias simples a partir do sexto setígero e com até três filamentos em parapódios medianos. Cirros ventrais cirriformes até o quinto setígero, transicional no sexto e em almofada nos seguintes. Lobos pós-setais digitiformes nos primeiros 10 setígeros. Ganchos pseudocompostos tridentados, com dente distal pouco mais desenvolvido que o mediano, nos quatro setígeros anteriores. Após o quinto setígero, ganchos pseudocompostos substituídos por cerdas limbadas. Grandes ganchos medianos tridentados, com dentes mediano e proximal robustos, presentes do terceiro ao sexto setígeros. A partir do $13^{\circ}$ setígero, aparecem ganchos sub-aciculares bidentados.

Distribuição. Atlântico Sul: Brasil, costa sudeste (Paraná e São Paulo) e Argentina.

Discussão. O exemplar examinado apresenta caracteres que correspondem estreitamente à descrição original de FAUCHALD (1982a). Kinbergonuphis orensan$z i$ (Fauchald, 1982) distingue-se das demais espécies do gênero por apresentar menor número de setígeros anteriores providos de cirros ventrais cirriformes e de grandes ganchos medianos tridentados (Tab. I). Onuphis (=Kinbergonuphis) oligobranchiata, descrita por ORENSANZ (1974) para a Argentina, é espécie próxima. Diferencia-se no entanto de $K$. orensanzi, pelo reduzido número de brânquias cirriformes delgadas em poucos segmentos médio-anteriores $\left(6^{\circ} / 7^{\circ}-10^{\circ} / 18^{\circ}\right)$ e pela presença de ganchos pseudocompostos tridentados apenas nos dois ou três primeiros setígeros.

\section{Kinbergonuphis tenuis (Hansen, 1882)}

Tab. I

Onuphis temuis Hansen, 1882: 10. - Orensanz, 1974: 87-89, est. 3, figs 1-11.

Kinbergonuphis tenuis; Fauchald, 1982b: 13-14, fig. 5c.

Material examinado. Seis exemplares incompletos; o maior com 125 setígeros, medindo $23 \mathrm{~mm}$ de comprimento. Em fundos de areia fina, silte grosso e médio; de 10 a $50 \mathrm{~m}$ de profundidade. 
Descrição. Ceratóforos das antenas dorsais com 4-5 anelações: ceratóstilos das antenas laterais posteriores atingindo o $4-7^{\circ}$ setígero. Brânquias ramificadas, com dois filamentos, presentes a partir do sexto setígero, atingindo até três filamentos em parapódios medianos. Cirros ventrais cirriformes nos seis primeiros setígeros. Lobos pós-setais digitiformes do primeiro ao $10-12^{\circ}$ setígero. Ganchos pseudo-compostos tridentados com dente distal relativamente longo, nos cinco primeiros setígeros; no sexto setígero pode haver um único grande gancho pseudocomposto mediano com dentes mais curtos e robustos. Ganchos subaciculares bidentados a partir do $14-15^{\circ}$ setígero.

Distribuição. Atlântico Sul: Brasil, costa sudeste (São Paulo) e Uruguai.

Discussão. Kinbergonuphis tenuis foi originalmente descrita por HANSEN (1882) para o Rio de Janeiro, como Onuphis tenuis. Os exemplares aqui estudados diferenciam-se em alguns aspectos dos espécimens do Rio de Janeiro, revistos e redescritos por FAUCHALD (1982b), mas correspondem perfeitamente à descrição feita por ORENSANZ (1974) para O. tenuis da costa uruguaia (Tab. I): cirros ventrais cirriformes e lobos pós-setais digitiformes restritos a um menor número de setígeros do que o mencionado por Fauchald, e presença de um gancho com articulação menos desenvolvida e dentes mais curtos no quinto setígero. PAXTON (1986), ao rever o material tipo de Hansen, constatou a presença de grandes ganchos medianos nos setígeros 6-8, provavelmente não observados por Fauchald. Segundo Paxton, esses ganchos têm desenvolvimento tardio e portanto, podem estar ausentes em indivíduos jovens. Sendo assim, ganchos medianos mais robustos, providos de pseudo articulação e dente distal curto, têm sido considerados precursores dos ganchos simples tridentados e, conseqüentemente, incluídos na terminologia proposta por PAXTON (1986), "grandes ganchos medianos".

\section{Mooreonuphis Fauchald, 1982}

\section{Mooreonuphis intermedia (Kinberg, 1865)}

\section{Tab. II}

Onuphis fragilis Kinberg, 1865: 561. - Orensanz, 1974: 94-95, est. 7, figs 1-13.

Onuphis intermedia Kinberg, 1865: 560.

Onuphis (Nothria) intermedia; Fauchald, 1980: 806-807, tab. II.

Mooreonuphis intermedia; Fauchald, 1982b: 60, fig. 17e. - Lana, 1984: 155-158, figs 165-168. - Lana, 1991: 291.

Material examinado. Cinco exemplares, dos quais um completo, com 125 setígeros e medindo $25 \mathrm{~mm}$ de comprimento. Em fundos de areia média, fina e muito fina, entre 25 e $45 \mathrm{~m}$ de profundidade.

Descrição. Região dorsal anterior com característico padrão de pigmentação castanha no peristômio e, em faixas transversais intersegmentares, na região mediano-dorsal dos setígeros anteriores. Prostômio subtriangular com dois pares de manchas ocelares; um par anterior, junto às bases dos palpos frontais e outro junto às bases das antenas laterais posteriores. Antenas dorsais com ceratóforos indistintamente anelados e ceratóstilos afilados, o mais longo atingindo o $5-7^{\circ}$ setígeros. 
Brânquias simples a partir do $10^{\circ}$ setígero, estendendo-se até próximo à extremidade posterior do corpo. Cirros dorsais subulados; cirros ventrais cirriformes nos três ou quatro primeiros setígeros. Lobos pós-setais digitiformes nos 12-13 setígeros anteriores, cônicos nos demais. Ganchos pseudocompostos tridentados com dente proximal reduzido, nos três primeiros setígeros. Sem grandes ganchøs medianos em setígeros anteriores. Espinígeras compostas com artículo curto, presentes do quarto ao $14^{\circ}$ setígero. Ganchos sub-aciculares bidentados substituem as cerdlas espinígeras a partir do $15^{\circ}$ setígero.

Distribuição. Atlântico Sul, do Sudeste do Brasill (Rio de Jameiro) à Argentina (Rio da Prata).

Discussão. Alguns problemas taxonômicos existem em tormo de Mooreonuphis intermedia. Onuphis intermedia, descrita por KINBERG (1865) para o Rio de Janeiro, foi revista por AUGENER (1931) e posteriormente por FAUCHALD (1980, 1982b). Segundo Fauchald, a descrição de Augener, com base no material tipo, não corresponde à espécie de Kinberg, pois não concorda com a descrição original nem com as ilustrações publicadas por KINBERG (1910), o que sugere que Augener tenha se baseado em material distinto do original. Onuphis intermedia foi ainda relacionada ao subgênero Nothria por FAUCHALD (1980), que posteriormente a incluiu no novo gênero Mooreonuphis criado quando de sua revisão dos Onuphidae em 1982.

Mooreonuphis intermedia pertence, juntamente com $M$. cirrata $(=$ Nothria stigmatis cirrata Hartman, 1944), M. dangrigae (Fauchald, 1980) e M. guadalupensis (= Nothria guadalupensis Fauchald, 1968), ao grupo de espécies que se caracteriza por apresentar brânquias sempre simples a partir de setígeros mais posteriores, e pela ausência de grandes ganchos medianos simples (Tab. II). Mooreonuphis intermedia distingue-se de suas congêneres pela presença de brânquias em setígeros relativamente mais anteriores $\left(10^{\circ}\right)$ bem como por menor número de setígeros com ganchos pseudocompostos tridentados (Tab. II).

Tabela II. Comparação das espécies de Mooreonuphis com brânquias simples a partir do $10^{\circ}$ setígero e sem grandes ganchos medianos, com $M$. intermedia (única espécie referida no presente trabalho).

\begin{tabular}{|c|c|c|c|c|c|c|c|c|}
\hline \multirow{3}{*}{$\begin{array}{l}\text { Espécies e } \\
\text { referéncias }\end{array}$} & \multirow{3}{*}{$\begin{array}{l}\text { Ceratỏforo } \\
\text { número } \\
\text { máximo de } \\
\text { anéis }\end{array}$} & \multirow{3}{*}{$\begin{array}{c}\text { Brånquias, } \\
1^{\circ} \text { par no } \\
\text { setigero }\end{array}$} & \multicolumn{3}{|c|}{ Presente nos setigeros } & \multicolumn{3}{|c|}{ Ganchos } \\
\hline & & & \multirow{2}{*}{$\begin{array}{c}\text { Cirro } \\
\text { ventral } \\
\text { cirriforme }\end{array}$} & \multirow{2}{*}{$\begin{array}{l}\text { Lobo } \\
\text { pós-setal } \\
\text { digitiforme }\end{array}$} & \multirow{2}{*}{$\begin{array}{l}\text { Cerdas } \\
\text { compostas } \\
\text { espinigeras }\end{array}$} & \multicolumn{2}{|c|}{ Pseudocompostos } & \multirow{2}{*}{$\begin{array}{c}\text { Subaciculares } \\
\begin{array}{c}\text { A partir dos } \\
\text { setigeros }\end{array}\end{array}$} \\
\hline & & & & & & $\begin{array}{l}\text { Número } \\
\text { setigeros }\end{array}$ & $\begin{array}{l}\text { Número } \\
\text { dentes }\end{array}$ & \\
\hline \multicolumn{9}{|l|}{ M. cirrata } \\
\hline HARTMAN (1944) & 5 & $17-18$ & $1-6$ & $1-24$ & $6-16$ & 5 & 3 & 17 \\
\hline \multicolumn{9}{|l|}{ M. dangrigae } \\
\hline $\begin{array}{l}\text { FAuchaLD (1980) } \\
\text { M. guadalupensis }\end{array}$ & $4-5$ & $18-21$ & $1-4 / 5$ & $1-45$ & $6-14 / 16$ & 5 & 2 e 3 & $15-17$ \\
\hline FAUCHALD $(1982 b)$ & Liso & $22-24$ & $1-3$ & $1-9 / 12$ & $4-13$ & 4 & 2 e 3 & $12-13$ \\
\hline \multicolumn{9}{|l|}{ Onuphis fragilis } \\
\hline Orensanz (1974) & Liso & $10-21$ & $1-3 / 4$ & $1-11 / 13$ & $4 / 5-13 / 15$ & 3 & 3 & $14-16$ \\
\hline \multicolumn{9}{|l|}{ M. Intermedia } \\
\hline FAUCHALD $(1980)$ & $4-5$ & 25 & $1-5$ & Não obs. & $4-13$ & 3 & 3 & 13 \\
\hline LANA (1984) & $4-5$ & $8-25$ & $1-4$ & $1-12 / 13$ & $4-13$ & 3 & 3 & $12-14$ \\
\hline MORGADO \& AMARAL & Indistinto & 10 & $1 / 3-4$ & $1-12 / 13$ & $4-14$ & 3 & 3 & 15 \\
\hline
\end{tabular}

*. Segundo ORENSANZ (1974) em O. fragilis o terceiro e quarto setígeros podem ter 1 -2 ganchos simples tridentados. 
Onuphis fragilis Kinberg (1865) referida por ORENSANZ (1974) para a Argentina e não incluída por FAUCHALD (1982b) na análise do complexo OnuphisNothria-Paradiopatra, é aqui considerada idêntica à Mooreonuphis intermedia.

Os exemplares examinados concordam perfeitamente com a descrição de $M$. intermedia fornecida por LANA (1984) para espécimens do litoral paranaense. Apresentam divergência com relação às descrições de FAUCHALD (1980, 1982b), apenas no que se refere ao setígero de aparecimento das brânquias $\left(25^{\circ}\right)$, caráter sujeito a ampla variabilidade intraespecífica, conforme mencionado por LANA (1984), que registra a ocorrência excepcional do início das brânquias entre os setígeros $8-9^{\circ}$ ao $25^{\circ}$.

\section{Mooreonuphis nebulosa (Moore, 1911)}

Onuphis nebulosa Moore, 1911: 269-273, est. 17, figs 58-68. - Hartman, 1944: 75, figs 76-85. - Nonato, 1981: 120-121.

Mooreonuphis nebulosa; Fauchald, 1982b: 56-57, fig. 17a.

Material examinado. Oito exemplares incompletos; o maior com 110 setígeros, medindo $48 \mathrm{~mm}$ de comprimento. A $10 \mathrm{~m}$ de profundidade, junto à Ilha Anchieta.

Descrição. Prostômio com distinto padrão de pigmentação: manchas irregulares na base da antena mediana e laterais posteriores, e manchas punctiformes na base dos palpos frontais; faixa de pigmento na base dos ceratóstilos de todas as antenas e junto à extremidade dos ceratóstilos das antenas mediana e laterais posteriores. Antenas laterais posteriores, mais longas, atingindo o $4-5^{\circ}$ setígero. Ceratóforos de todas as antenas, com quatro anelações. Parapódios do $8-9^{\circ}$ primeiros setígeros mais desenvolvidos que os restantes. Brânquias cirriformes aparecem no sexto setígero, tornando-se ramificadas, com até cinco filamentos, nos setígeros posteriores. Cirros ventrais cirriformes do primeiro ao $11-12^{\circ}$ setígeros. Lobos pós-setais distintos, ao longo de aproximadamente 22 setígeros. Ganchos pseudocompostos tridentados nos primeiros 9-11 setígeros. Grandes ganchos medianos tridentados simples presentes do $7-8^{\circ}$ ao $19-20^{\circ}$ setígeros. Cerdas compostas espinígeras do $10-12^{\circ}$ até o $20-21^{\circ}$ setígeros. Ganchos sub-aciculares bidentados a partir do $20-21^{\circ}$ setígero.

\section{Distribuição. Pacífico e Atlântico americanos.}

Discussăo. Moorenuphis nebulosa (Moore, 1911), amplamente registrada no Atlântico e Pacífico americanos, é espécie frequente em dragagens costeiras no litoral de São Paulo e Rio de Janeiro (NONATO 1981). Caracteriza-se pela ocorrência de brânquias a partir do sexto setígero e pelo elevado número de setígeros modificados (8-9), dotados de grandes ganchos medianos. Mooreonuphis litoralis (Monro, 1933), M. microbranchiata (Fauchald, 1968) e M. lineata Lana (1991) são espécies próximas por também apresentarem brânquias ramificadas e grandes ganchos medianos. As duas primeiras diferenciam-se claramente de $M$. nebulosa pela presença de brânquias somente a partir de setígeros mais posteriores $\left(16-19^{\circ}\right.$ e $13^{\circ}$, respectivamente), e $M$. lineata por apresentar brânquias pectinadas mais desenvolvidas (até seis filamentos) e maior número de setígeros anteriores providos de ganchos medianos tridentados $\left(2-22^{\circ}\right)$. 
Todos os exemplares registrados neste estudo são provenientes de uma mesma amostra o que segundo HARTMAN (1944), poderia estar relacionado à existência de hábito gregário nessa espécie.

\section{Mooreonuphis pallidula (Hartman, 1965)}

Nothria pallidula Hartman, 1965: 105-106, est. 17, figs d-h.

Mooreonuphis pallidula; Fauchald, 1982b: 62, fig. 17b.

Material examinado. Um exemplar incompleto de 77 setígeros e medindo $22 \mathrm{~mm}$ de comprimento. Em fundo de areia muito fina, a $35 \mathrm{~m}$ de profundidade.

Descrição. Forma relativamente robusta. Prostômio com um par de manchas ocelares punctiformes entre as bases das antenas laterais. Antenas dorsais mais longas atingindo o sétimo setígero, providas de ceratóforos com até cinco anelações. Parapódios dos três primeiros setígeros maiores que os demais, dirigidos lateralmente. Brânquias simples, cirriformes, presentes a partir do sexto setígero e estendendo-se até a região posterior. Cirros ventrais cirriformes nos primeiros cinco setígeros e em "almofada", nos demais. Lobos pós-setais digitiformes distintos nos 15 setígeros anteriores. Ganchos pseudocompostos distalmente tridentados, acompanhados por cerdas limbadas dorsais até o quinto setígero. Grandes ganchos medianos, não observados em setígeros anteriores. Espinígeras compostas substituem os ganchos pseudocompostos, do sexto ao $17^{\circ}$ setígero, até o aparecimento de ganchos sub-aciculares bidentados, a partir de $18^{\circ}$ setígero.

Distribuição. Costa atlântica dos Estados Unidos e Brasil (São Paulo).

Discussão. O exemplar analisado corresponde perfeitamente à espécie referida como Nothria pallidula, originalmente descrita por HARTMAN (1965), e à descrição de FAUCHALD (1982b). Mooreonuphis pallidula distingue-se das espécies congêneres pela presença de brânquias sempre simples, cirriformes, a partir do sexto setígero e pelo início de ganchos sub-aciculares em setígeros relativamente mais posteriores. Mooreonuphis intermedia, também assinalada na área estudada, é espécie próxima, mas dela diferencia-se quanto ao aparecimento das primeiras brânquias $\left(10^{\circ}\right.$ setígero), e dos ganchos sub-aciculares ( $15^{\circ}$ setígero). A ocorrência desta espécie em águas brasileiras amplia sua distribuição ao atlântico sul.

\section{Onuphis Audouin \& Milne Edwards, 1833}

\section{Onuphis dibranchiata Willey, 1905}

Onuphis dibranchiata Willey, 1905: 277-278, est. 4, fig. 100. - Fauvel, 1953: 254. - Fauchald, 1982b: 44-45.

Material examinado. Um exemplar incompleto com 39 setígeros e aproximadamente $8 \mathrm{~mm}$ de comprimento. A $10 \mathrm{~m}$ de profundidade, próximo à Ilha Anchieta.

Descrição. Forma pequena, com um característico padrão de pigmentação castanha na região anterior: manchas na metade inferior dos ceratóforos e na base dos cerastóstilos das antenas mediana e laterais posteriores, e em faixas tranversais, no peristômio. Antenas longas, com ceratóforos providos de até 15 anéis: ceratóstilos mais longos que os ceratóforos, exceto nas antenas laterais anteriores. Brân- 
quias simples, filamentosas, no primeiro setígero, tornando-se bífidas e mais longas que os cirros dorsais, a partir do $21^{\circ}$ setígero. Cirro ventral cirriforme nos seis primeiros setígeros. Lobos pós-setais digitiformes, longos até o $10^{\circ}$ setígero e cônicos nos dois setígeros seguintes. Ganchos pseudocompostos distalmente bi e tridentados, de diferentes tamanhos, do primeiro ao terceiro setígero, substituídos por cerdas limbadas a partir do quarto. Ganchos sub-aciculares bidentados presentes a partir do $10^{\circ}$ setígero. Paulo).

Distribuição. Oceano Índico (Sri Lanka) e Atlântico Ocidental (Brasil, São

Discussão. Onuphis dibranchiata Willey, 1905, conhecida até o presente apenas da localidade do material tipo, Sri Lanka, no Oceano Índico, caracteriza-se pela presença de brânquias já no primeiro setígero que atingem um número máximo de dois filamentos quando melhor desenvolvidas, e por possuir ganchos pseudocompostos bi e tridentados. Onuphis elegans (Johnson, 1901), O. farallonensis Hobson, 1971 e O. shirikisphianaienisis (Imajima, 1960) são espécies próximas por também apresentarem brânquias a partir do primeiro setígero e ganchos pseudocompostos bi e tridentados. Diferem de $O$. dibranchiata principalmente por possuirem brânquias sempre simples.

\section{REFERÊNCIAS BIBLIOGRÁFICAS}

Augener, H. 1931. Die bodensässigen Polychaeten nebst einer Hirudinee der Meteor-Fahrt. Mitt. Zool. Staatsinst. Hamb. 44: 279-313.

BosC, L.A.G. 1802. Histoire naturelle des vers, contenant leur description et leurs moeurs; avec figures dessinées d'après nature. Paris, Deterville, vol. 1, $324 \mathrm{p}$.

DAY, J.H. 1967. Polychaeta of Southern Africa. Part I. Errantia. London, British Mus. (Nat. Hist.), 458p.

FAUCHALD, K. 1980. Onuphidae (Polychaeta) from Belize, Central America, with notes on related taxa. Proc. Biol. Soc. Wash. 93 (3): 797-829.

- 1982a. Two new species of Onuphis (Onuphidae: Polychaeta) from Uruguay. Proc. Biol. Soc. Wash. 95 (1): 203-209.

. 1982b. Revision of Onuphis, Nothria and Paradiopatra (Polychaeta: Onuphidae) based upon type material. Smiths. Contr. Zool. 356: 1-109.

FaUvel, P. 1923. Polychètes Errantes. Faune de France, Lechevallier, 5: $1-488$.

1953. Annelida Polychaeta. The fauna of India including Pakistan, Ceylon, Burna and Malaya. Allahabad, The Indian Press, 507p.

GARDINER, S.L. 1975. Errant polychaete annelids from North Carolina. Jour. Elisha Mitchell. Sci. Soc. 91(3): 77-220 [1976].

GathoF. J.M. 1984. Onuphidae, p.39.1-39.35. In: J.M. Uebelacker \& P.G. JOHNSON (Eds). Taxonomic guide to the polychaetes of the northern Gulf of Mexico. Louisiana, Barry A. Victor and Associates, VI+39.1-48-4.

HANSEN, A. 1882. Recherches sur les Annélides recueillies par M. le Professeur Edouard Van Beneden pendant son voyage au Brésil et à la Plata. Mém. Cour. Acad. Roy. Sci. Belgique 44 (3): 1-29. 
Hartman, O. 1944. Polychaetous annelids. Pt. V. Eunicea. Allan Hancock Pacific Exped. 10 (1): 1-238.

- 1965. Deep-water benthic polychaetous annelids off New England to Bermuda and other North Atlantic areas. Occ. Pap. Allan Hancock Fdn. (28): $1-378$.

KinberG, J.G.H. 1865. Annulata nova. Förh. Oefv. Svenska. Vet. Akad., Stockholm, 21: 559-574.

1910. Kongliga Syenska Fregatten "Eugenies" Resa omkring jordem

under befäl af C.A. Virgin ären 1851-1853. Zoologi 3. Annulater. Uppsala \& Stockholm, Almquist \& Wicksells, 78p.

LANA, P.C. 1984. Anelídeos Poliquetas Errantes do litoral do Estado do Paraná.

Tese de Doutorado, não publicada, Instituto Oceanográfico, Universidade de São Paulo, São Paulo, 275p.

1991. Onuphidae (Annelida: Polychaeta) from Southeastern Brazil. Bull. Mar. Sci. 48 (2): 280-295.

MOORE, J.P. 1911. The polychaetus annelids dredged by the U.S.S. Albatross off the Coast of Southern California in 1904, III: Euphrosynidae to Goniadidae.

Proc. Acad. nat. Sci. Philad. 58: 217-260.

NonAto, E.F. 1981. Contribuição ao Conhecimento dos Anelídeos Poliquetas

Bentônicos da Plataforma Continental Brasileira, entre Cabo Frio e o

Arroio Chuí. Tese de Livre Docência, não publicada, Instituto Oceanográfico, Universidade de São Paulo, São Paulo, 246p.

NonAto, E.F. \& J.A.C. LUNA. 1970. Anelideos poliquetas do Nordeste do Brasil.

I Poliquetas bentônicos da costa de Alagoas e Sergipe. Bolm. Inst. oceanogr.,

São Paulo, 19: 57-130.

ORENSANZ, J.M. 1974. Los anelidos poliquetos de la provincia biogeográfica Argentina. V. Onuphidae. Physis A, Buenos Aires, 33 (86): 75-122.

Subantartic Seas, p. 1-183. In: L.S. KORNICKER (Ed.). Biology of the Antartic

Seas XXI. Washington, Antartic Research Series, 52/1+236p.

PAXTON, H. 1986. Generic revision and relationships of the family Onuphidae

(Annelida: Polychaeta). Rec. Austr. Mus. 38 (1): 1-74.

PetTiBone, M.H. 1963. Marine Polychaete worms of the New England Region. 1. Aphroditidae through Trochochaetidae. Bull. U.S. Nat. Mus. 227 (1): 1-356.

TEMPERINI, M.T. 1981. Sistemática e distribuição dos poliquetos errantes da

Plataforma Continental entre as latitudes de $23^{\circ} 05^{\prime} \mathrm{S}$ e $30^{\circ} 00^{\prime} \mathrm{S}$. Dissertação de Mestrado, não publicada, Instituto Oceanográfico, Universidade de São Paulo, São Paulo, 89p.

Willey, A. 1905. Supplementary Report, XXX: Report on the Polychaeta Collected by Professor Herdman, at Ceylon in 1902. In: Report to the Government of Ceylon on the Pearl Oyster Fisheries of the Gulf of Manaar by W.A. Herdman, D. Sc., F.R.S., P.L.S. with Supplementary Reports upon the Marine Biology of Ceylon by other Naturalists, 4: 243-324.

Recebido em 19.VII.1996; aceito em 13.II.1997. 